\title{
Dance and Movement Therapy in a Mental Health Rehabilitation Centre in South India
}

\author{
Aruna Rose Mary Kapanee ${ }^{1}$, Janavi Ananthapadmanabhan ${ }^{2}$, Tripura Kashyap ${ }^{3}$ \\ ${ }^{1}$ Assistant Professor, Dept. of Clinical Psychology, NIMHANS \\ ${ }^{2}$ Creative Movement Therapy Practitioner, Member,Creative Movement Therapy Association of India \\ (CMTAI) \\ ${ }^{3}$ Co-founder, Creative Movement Therapy Association of India (CMTAI) \\ Corresponding author: Aruna Rose Mary Kapanee \\ Email-arunarmkapanee@gmail.com
}

\begin{abstract}
Dance and Movement Therapy as an adjunct therapeutic method in the recovery and rehabilitation of persons with mental illness was utilized in a Mental Health Rehabilitation Centre in South India. This creative and expressive arts therapy was employed with an interdisciplinary approach to address, in persons with mental illness, the therapeutic goals of enhancing psychosomatic awareness, mind-body integration, body coordination and control, self-reflection, self-confidence, self-expression, cognitive skills, social skills, and teamwork skills. The paper describes the structure, composition and process of these Dance and Movement Therapy group sessions as well as details the therapeutic techniques employed.
\end{abstract}

Key words: Dance and Movement Therapy, Mental Health Rehabilitation, Persons with Mental Illness

(Paper received $-3^{\text {rd }}$ December 2017, Peer review completed $-10^{\text {th }}$ December 2017)

(Accepted $-19^{\text {th }}$ December 2017)

\section{INTRODUCTION}

Dance and Movement Therapy (DMT) as an adjunct therapeutic method for persons with mental illness (PWMI), was utilized in a Mental Health Rehabilitation Centre in South India. The aim of introducing the creative and expressive arts modality of DMT was to aid the recovery and rehabilitation of PWMI by enhancing through this therapeutic methodology, their body awareness, body coordination and control, mind-body integration, social skills, cognitive skills, interpersonal belongingness and self-expression.

\section{STRUCTURE AND COMPOSITION OF THE DMT GROUP}

The DMT sessions were held in groups. The sessions were for the PWMI utilizing the in-patient rehabilitation services of a Mental Health Rehabilitation Centre in South India. Thus as PWMI joined or left the centre the group constitution would change, making the group dynamic/open in nature.

The sessions were for duration of one hour. They were initially held once a week and were later held twice every week for a period of 6 months. The groups were heterogeneous in nature. The group comprised of adult males and females. The group members differed in terms of their education, relationship status, socioeconomic, religious and cultural background, as well as their psychiatric diagnosis. The varied cultural background of the group members lead to difficulty in terms of communication due to the different Indian languages that each participant spoke. In spite of this the group was largely cohesive, as 
the participants were engaged in several other activities as a group in the centre and thus shared a great degree of familiarity and bonding.

\section{GOALS OF THE DMT SESSIONS}

The goals of the sessions attempted to incorporate as much as possible the needs of the various group members. The Clinical Psychologists, who were engaged in- individual, couple/family and grouppsychotherapy with the PWMI, worked in conjunction with the therapists conducting the DMT sessions so that the psychotherapeutic goals of the PWMI could be incorporated and addressed through the DMT medium too.

The goals of the DMT sessions included enhancing body awareness, body coordination and control, emotional awareness, self-reflection, self-awareness, self-confidence, motivation, self-expression, anger management, cognitive skills, social skills, and team work skills. Other goals addressed through these sessions were impulse control and channelizing of hyper energetic behavior. The DMT therapists formulated and conducted movement activities that addressed these various goals.

Each session had constellations of solo, duo and group activities so that it made the participants feel comfortable in their preferred manner and also motivated them to challenge themselves to come out of their comfort zone.

\section{DMT TECHNIQUES AND ACTIVITIES}

The DMT techniques and activities utilized in these group sessions are discussed below under broad focus areas:

\section{Attunement}

This focused on creating a connection or bond between two or more aspects within an individual and with others in the group through various activities. Activities that incorporated attunement included having the pairs of participants face each other with established boundaries around them. The boundaries were made with objects such as a 'dupatta' (long piece of cloth similar to a stole). Each pair was requested to make eye contact and create a movement. Another activity that incorporated attunement was 'Shadowing', in which again the participants were divided into pairs, in which one member was the lead and the other was the follower. Each member of the pair would take turns to be lead and follower. The member who was the follower had to move behind the lead and copy the movements of the lead. In shadowing, thus there was no eye contact between members of a pair.

\section{Mirroring}

This is an effective way to address self and other awareness, improve attention and concentration, as well as enhance one of the most basic social skills of eye-to-eye contact. It helps create ease among group members who are new to moving without a structure or guide, as it is not abstract. In 'mirroring' the group is divided into pairs, and each pair is requested to create a reflection of each other for each other. Thus, one is the 'doer' and the other is the 'mirror' or 'reflector'. In this technique, the members of the pair face each other and eye contact is essential. The reflection could be of a movement, and/or an emotion. For e.g. the therapist would give the instructions that imagine you are walking in a park and you are angry. The 'doer' thus had to create this emotion and an associated movement and the 'mirror' had to reflect the 'doer'. Each member of the pair would take turns to be the 'doer' and 'mirror', which would lead each participant to feel satisfied to observe his/her movements and emotions reflected with its authenticity.

\section{Rhythm development}

This included activities in which each group member contributed a sound/movement individually and then as a group they created a sound/movement rhythm. This enabled the development of teamwork skills as it gave the group members an opportunity to contribute and follow a team activity. It also nurtured group cohesion as the participants felt the joy of creating something, as well as a sense of ownership of a 
creative and tangible piece of work. In terms of cognitive skills it focused on the strengthening of attention, concentration, motor coordination as well as auditory/visual learning and memory.

\section{Creative Visualization}

This was used in order to provide each group member a platform to visualize and express their thoughts and desires through movement. A technique utilized here was of painting wherein the body was considered as the brush and the space around as the canvas. This was a solo activity in which each group member had the freedom to paint the space around him or her according to the colour, image and movement of their choice. For a number of group members this exercise provided the opportunity to expand their body-space awareness as well as imagine and experience the actualization of their aspirations.

\section{Movement language}

This focused on building awareness of the discrepancy between thoughts, emotions, physical experience and verbal/non-verbal expression. One of the techniques which was used to develop synchronicity in these various aspects was by having a 'feeling' chart, wherein each group member had to choose a word to express how they felt that day. With time, they were also required to express the feeling with a movement. This enabled the verbal and non-verbal expression and acceptance of the feeling as well as aided the individual to develop a repertoire in which the expression was in sync with the internal cognitive and felt experience.

\section{PROCESS OF THE DMT SESSIONS}

The sessions would begin with a Check-in. A Check-in meant that each participant had to inform the rest of the group how they felt at the moment. This aided the therapist to tailor the session according to the groups' present state of mind. The therapist then led the group through a set of warm-up exercises. This was followed by engaging in solo, duo and group activities based on the goals of the session.

The therapist provided verbal prompts to the participants as and when required in order to help them to explore the range of body movements and emotions. The therapist also questioned the participants in an open-ended or close-ended manner, at various points in order to elicit responses that would assist them to describe and differentiate their experiences and build self-awareness.

Based on the activity being done the therapist utilized props such as balls, balloons, streamers, sticks, scarfs, 'dupattas', paper, pencils, and colour pencils. The therapist found that activities with props tended to be more effective than activities with just movements and verbal processing. Music helped in building the connection between the therapist and the group members. The participants responded well to activities guided with music. Visual art use of drawings and writing was easier for some members of the group while others preferred expressing or sharing verbally.

The closure of each session was a ritual of free dancing on movie songs, followed by a cooling down exercise.

\section{CONCLUSION}

Dance and Movement Therapy was one of the mental health care services offered to the persons with mental illness availing inpatient services in a Mental Health Rehabilitation Centre in South India along with psychopharmacological, psychotherapeutic and psychosocial interventions. A variety of DMT techniques such as shadowing, mirroring, creative visualization were employed with the goals of enhancing psychosomatic awareness, mind-body integration, body coordination, self-reflection, selfawareness, self-confidence, self-expression, cognitive skills, social skills and teamwork skills. An interdisciplinary approach, which incorporated a creative and expressive arts modality of Dance and Movement Therapy was therefore utilized in addressing the recovery and rehabilitation goals of the persons with mental illness. 


\section{RECOMMENDED READING}

1. Stanton-Jones K. An introduction to dance movement therapy in psychiatry. Taylor \& Francis; 1992.

2. Payne H. Dance movement therapy: Theory and practice. Routledge; 2003.

3. Ritter M, Low KG. Effects of dance/movement therapy: A meta-analysis. The Arts in Psychotherapy 1996;23(3):249-60.

4. Bernstein P. Theory and methods in dance-movement therapy. Kendall/Hunt Publishing Company; 1981.

5. Chaiklin $\mathrm{S}$, Wengrower $\mathrm{H}$, editors. The art and science of dance/movement therapy: Life is dance. Routledge; 2015.

6. Pylvänäinen P. Body image: A tripartite model for use in dance/movement therapy. Am J Dance Therapy 2003;25(1):39-55.

7. Meekums B. Dance movement therapy: A creative psychotherapeutic approach. Sage; 2002.

8. Hervey LW. Artistic inquiry in dance/movement therapy: Creative research alternatives. Charles $C$ Thomas Publisher; 2000.

9. Goodill S. An introduction to medical dance/movement therapy: Health care in motion. Jessica Kingsley Publishers; 2005.

10. Meekums B, Karkou V, Nelson A. Dance movement therapy for depression. Cochrane Database of Systematic Reviews 2015;19(2):1-54.

\section{Acknowledgments}

Authors would like to acknowledge the support of the multidisciplinary team of the Mental Health Rehabilitation Centre.

Financial support and sponsorship - Nil.

Conflicts of interest - Nil. 